\title{
Sleep Organization and Energy Expenditure of Breast-Fed and Formula-Fed Infants ${ }^{1}$
}

\author{
NANCY F. BUTTE, CRAIG L. JENSEN, JON K. MOON, DANIEL G. GLAZE, AND \\ JAMES D. FROST, JR. \\ Children's Nutrition Research Center, Department of Pediatrics, Department of Neurology, Baylor College of \\ Medicine, and Neurophysiology Service, The Methodist Hospital, Houston, Texas 77030
}

\begin{abstract}
Sleep organization of infants may be influenced by differences in nutrient intakes from human milk and formula. Because sleep/awake and sleep stage patterns affect energy expenditure, we hypothesized that differences in sleep organization between breast-fed and formula-fed infants might account in part for differences in energy expenditure between feeding groups. Sleep stages and cycling of 4-mo-old breast-fed $(n=10)$ formula-fed $(n=10)$ infants were studied with simultaneous measurements of energy expenditure. EEG, electrooculogram, body movement by triaxial accelerometry, heart rate, and oxygen saturation were monitored during an overnight sleep session. Sleep stages, nonrapid eye movement (NREM), and rapid eye movement (REM) were determined. Behavioral observations were recorded by video tape and by a technologist. Oxygen consumption and carbon dioxide production were measured with an indirect calorimeter. Total number and duration of sleep cycles, REM latency, number of NREM and REM epochs, and duration of NREM epochs did not differ between feeding groups. Sleep latency was shorter $(p<0.05)$ and duration of REM epochs longer $(p<0.01)$ in the formula-fed group. Formula-fed infants spent a higher percentage of sleep time in REM compared with the breast-fed infants $(42$ versus $34 \%)(p<0.003)$. Conversely, breast-fed infants spent a higher percentage of sleep time in NREM sleep and their heart rates during sleep were lower $(114$ versus $126 \mathrm{bpm} ; p<0.01)$. Energy expenditure during REM sleep was $13.0 \pm 4.4 \%$ higher than during NREM sleep $(p<0.001)$. Nonetheless, total energy expenditure during REM and NREM sleep did not differ statistically between feeding groups, even though nocturnal sleep organization was affected by infant feeding mode and contributed to the measured variability in energy expenditure observed during sleep. (Pediatr Res 32: 514 $519,1992)$
\end{abstract}

\section{Abbreviations}

NREM, nonrapid eye movement

REM, rapid eye movement

AA, amino acid

$\dot{\mathrm{V}} \mathrm{O}_{2}$, oxygen consumption

$\dot{\mathrm{V}}_{2}$, carbon dioxide production

Received March 16, 1992; accepted July 8, 1992.

Correspondence: Nancy F. Butte, Ph.D., Children's Nutrition Research Center, 1100 Bates St., Houston, TX 77030.

This work is a publication of the USDA/ARS Children's Nutrition Research Center, Department of Pediatrics, Baylor College of Medicine, Houston, TX. This project has been funded in part with federal funds from the U.S. Department of Agriculture, Agricultural Research Service under Cooperative Agreement number 58-6250-1-003. The contents of this publication do not necessarily reflect the views or policies of the U.S. Department of Agriculture, nor does mention of trade names, commercial products, or organizations imply endorsement from the U.S. Government.
The sleep organization of infants may be influenced by qualitative and quantitative differences in nutrient intakes from human milk and formula. The synthesis of brain neurotransmitters involved in the induction and maintenance of sleep is influenced by normal postprandial fluctuations in the availability of AA (1). Transport of tryptophan, the precursor of serotonin, across the blood-brain barrier depends on the ratio of plasma tryptophan to the sum of large neutral AA that compete for the same active transport system. Plasma AA levels in breast-fed infants have been shown to differ from those in formula-fed infants; in particular, the plasma tryptophan and tryptophan/sum of large neutral AA levels were higher in the breast-fed than in the formula-fed infants (2). Diet-induced alterations in plasma AA ratios have, in fact, been shown to affect infant sleep behavior (3).

Infant state, defined as REM sleep, NREM sleep, or awake, is influenced not only by environmental factors such as nutrition, but also by maturation and development (1). During the first 4 mo of life, distinct changes occur in the organization of infant sleep; NREM sleep increases to approximately $60 \%$ and REM sleep decreases to approximately $40 \%$ of total sleep (4). The frequency of active sleep and quiet sleep cycling is approximately $1.0 \mathrm{cycles} / \mathrm{h}$ at 4 to $6 \mathrm{mo}$ of age (5). Electroencephalographic spindles are present at this time, and sleep onset shifts from the newborn mode of entry through REM sleep to the adult mode of entry through NREM sleep. During this time, circadian sleep patterns that have longer periods of unbroken sleep are established. These changes in infant sleep behavior reflect maturational changes in brain function (1).

We were interested in the sleep organization of infants fed human milk and formula, not only from a developmental perspective, but also from the perspective of the influence of sleep/ awake patterns and sleep stage distribution on the infant's energy expenditure. We have shown that total daily energy expenditure and sleeping metabolic rates of breast-fed infants are lower than those of formula-fed infants (6). Because various investigators have shown that energy expenditure of infants is higher during REM than NREM sleep (7-9), we hypothesized that differences in sleep stage distribution account partially for our observed differences in energy expenditure between breast-fed and formula-fed infants.

In an effort to explore the physiologic process associated with sleep and how they may be affected by infant feeding mode, we studied the sleep characteristics of 4-mo-old breast-fed and formula-fed infants and made simultaneous measurements of energy expenditure.

\section{MATERIALS AND METHODS}

Study design. Twenty (10 breast-fed and 10 formula-fed) healthy infants were studied at 4 mo of age. Infants and their mothers were admitted to the Clinical Research Center at The Methodist Hospital, Houston, TX, and transferred overnight to 
the Sleep Laboratory for characterization of infant sleep states and cycles and measurement of energy expenditure during sleep. A physical examination and anthropometric measurements were performed on each infant. A 5-d sleep diary and a 24-h assessment of infant intake were completed at home.

Physical examination. A complete physical examination, which included a neurologic assessment of the infant, was performed by a pediatrician. Vital signs (temperature, respiration, and pulse) were measured by a nurse.

Anthropometry. Weights of nude infants were obtained on electronic, integrating scales (model 3862MP, Sartorius, Gottingen, Germany) at least $1 \mathrm{~h}$ after feeding. Length was measured on a recumbent infant board.

Sleep monitoring. Infants were monitored overnight. Infants were transferred to the Sleep Laboratory at approximately 1900 h. The EEG technician applied the monitoring equipment with the assistance of the mother. After the equipment was applied and tested, the lights were dimmed and the mother fed her infant. Once asleep, the infant was placed in the calorimeter. Mothers slept in a nearby room and were available to feed and quiet their infants when awakened. Monitoring ended at $0600 \mathrm{~h}$. The sleep monitoring system used concurrent, graphically recorded data including two channels of EEG (C3-01, C4-02), two channels of electrooculogram, triaxial accelerometry, and oxygen saturation as detected by a pulse oximeter (Nellcor, Denver, CO) (10-12). Heart rate was obtained from the pulse oximeter; $1-m i n$ averages were stored in the microcomputer. A log of all behavioral changes or activities of the infant was kept by the EEG technician.

After the monitoring session, the graphic record was analyzed visually; total monitoring time was categorized into NREM, REM, and awake epochs using the EEG, electrooculogram, and triaxial accelerometry $(10-12)$. Sleep latency was defined as the time elapsed from completion of the application of monitoring equipment and cessation of interaction with the infant until the onset of sleep (NREM sleep occurred at sleep onset in all cases). REM latency was determined as the elapsed time from sleep onset until the first appearance of stage REM. When sleep cycle determinations were made, minor fluctuations lasting less than $2 \mathrm{~min}$ were ignored. Sleep transitions were taken as any change in infant state, regardless of duration.

Indirect calorimetry. $\dot{\mathrm{VO}}_{2}$ and $\dot{\mathrm{VCO}}_{2}$ were measured in an indirect calorimeter whenever the infants slept during the $10-\mathrm{h}$ monitoring period. The system consists of a transparent chamber of $105 \mathrm{~L}^{3}$, thermal-mass air flow meter (830, Sierra Institute, Monterey, CA), oxygen and carbon dioxide analyzers (Oxymat $5 \mathrm{E}$ and Ultramat $5 \mathrm{E}$, Siemens $\mathrm{AG}$, Karlsruhe, Germany), and a microcomputer (Portable 286, Compaq, Inc., Houston, TX). The calorimeter had an individual measurement accuracy of approximately $\pm 2 \%$ as determined by recoveries of oxygen and carbon dioxide from butane combustion and nitrogen/carbon dioxide infusion tests. Butane combustion checks were performed before each study. $\dot{\mathrm{V}}_{2}, \dot{\mathrm{V}}_{\mathrm{CO}_{2}}, \mathrm{RQ}\left(\mathrm{RQ}=\dot{\mathrm{V}}_{\mathrm{CO}_{2}} / \dot{\mathrm{V}}_{2}\right)$, and energy expenditure (energy expenditure $=3.941 \dot{\mathrm{VO}}_{2}+1.106$ $\left.\dot{\mathrm{V}}_{\mathrm{CO}}\right)(13)$ were calculated at 1 -min intervals.

Milk intake. Intake of human milk was assessed for $24 \mathrm{~h}$ at home by test-weighing (6); formula intake was determined from pre- and postweights of 4-fluid-ounce $(118 \mathrm{~mL})$ ready-to-feed bottles. Preweighed towels were provided to recover formula losses. Intake of food supplements, if given, was estimated by pre- and postweighing of feeding jars.

Human milk collection. A representative $24-\mathrm{h}$ milk sample was expressed using an electric breast pump (Egnell, Inc., Cary, IL), as described previously (6).

Milk analysis. The energy content of human milk and formula was determined in an adiabatic bomb calorimeter (Parr Instruments, Moline, IL). Nitrogen was analyzed by the Kjeldahl method before and after trichloroacetic acid precipitation of protein (Kjeltec Auto Analyzer 1030, Tecator, Hoganas, Sweden). Nonprotein nitrogen was determined on the supernatant, and protein nitrogen was estimated from the difference between total nitrogen and nonprotein nitrogen. Protein nitrogen was converted to protein using the factor 6.25. Lactose was determined using an automatic analyzer (model 127, YSI, Yellow Springs, OH). Fat was determined by the Jeejeebhoy method (14).

Statistical analysis. The Minitab Statistical Software program was used for data reduction and statistical analysis (15). Twosample $t$ tests and multiple regression were used to test for differences between feeding groups and examine relationships between variables. Analysis of variance with repeated measures was used to test for differences in energy expenditure and heart rate between feeding groups and sleep stages (BMDP2V) (16). All values are presented as the mean $\pm S D$.

\section{RESULTS}

Birth characteristics of the infants are shown in Table 1. All infants were full term, appropriate for gestational age, and healthy at birth. From birth through 4 mo of age, infants were reported to be healthy, except for a few minor illnesses. They had no unusual sleep problems.

At the time of study, the mean \pm SD age of the infants was $4.1 \pm 0.2 \mathrm{mo}$. Anthropometric measurements were similar between feeding groups. Weight and length averaged $6686 \pm 433 \mathrm{~g}$ and $64.5 \pm 2.1 \mathrm{~cm}$ for the breast-fed infants and $6609 \pm 810 \mathrm{~g}$ and $63.4 \pm 1.8 \mathrm{~cm}$ for the formula-fed infants. Weight gain was $2.3 \pm 0.9$ and $2.7 \pm 1.0 \mathrm{~g} \cdot \mathrm{kg}^{-1} \cdot \mathrm{d}^{-1}$ for the breast-fed and formulafed infants, respectively. Results of physical examination of the infants were unremarkable; neurologic assessments were normal. Vital signs were normal, although body temperatures $(36.8 \pm 0.4$ versus $\left.37.1 \pm 0.2^{\circ} \mathrm{C}\right)$ and heart rates $(134 \pm 10$ versus $141 \pm 6$ bpm) tended to be lower among the breast-fed than among the formula-fed infants $(p<0.06)$.

During our observations, the breast-fed infants received only human milk, although some mothers reported previous use of supplements. The mean intake of human milk, estimated from the 24 -h test-weighing at home, was $116 \pm 20 \mathrm{~g} \cdot \mathrm{kg}^{-1} \cdot \mathrm{d}^{-1}$. Formula-fed infants were given Similac (Ross Laboratories, Columbus, $\mathrm{OH})(n=5)$ or Similac with Iron $(n=5)$. Formula intake averaged $124 \pm 19 \mathrm{~g} \cdot \mathrm{kg}^{-1} \cdot \mathrm{d}^{-1}$. Cereal provided $6 \%$ of the energy intake of one formula-fed infant. Nutrient intakes, expressed on a body weight basis (Table 2), differed significantly between feeding groups $(p<0.05-0.001)$.

An infant sleep diary was kept by the mothers for $5.3 \pm 1.6 \mathrm{~d}$ preceding the study. Total sleep time did not differ between breast-fed $(13.2 \pm 2.3 \mathrm{~h} / \mathrm{d})$ and formula-fed $(13.3 \pm 0.9 \mathrm{~h} / \mathrm{d})$ infants. Usual nocturnal bedtime was $2106 \mathrm{~h} \pm 36 \mathrm{~min}$ and 2118 $\mathrm{h} \pm 90 \mathrm{~min}$ for the breast-fed and formula-fed infants, respectively. Nocturnal sleep time was uninterrupted from $8.2 \pm 1.6 \mathrm{~h}$ for breast-fed and $9.9 \pm 1.4 \mathrm{~h}$ for formula-fed infants $(p<0.04)$.

Nocturnal sleep characteristics determined during the monitoring study are summarized in Table 3. Total sleep time of the breast-fed infants, as a percentage of monitoring time, was less than that of the formula-fed infants $(p<0.04)$. During the monitoring study, the breast-fed infants were fed an average of

Table 1. Infant characteristics

\begin{tabular}{lcc}
\hline & $\begin{array}{c}\text { Breast-fed } \\
(n=10)\end{array}$ & $\begin{array}{c}\text { Formula-fed } \\
(n=10)\end{array}$ \\
\hline Birth weight $(\mathrm{g})$ & $3495 \pm 272^{*}$ & $3339 \pm 408$ \\
Birth length $(\mathrm{cm})$ & $51.0 \pm 2.0$ & $50.4 \pm 2.4$ \\
Sex (M/F) & $6 / 4$ & $4 / 6$ \\
Ethnicity (Caucasian/black/Hispanic) & $9 / 1 / 0$ & $6 / 3 / 1$ \\
Birth order & $1.5 \pm 0.7$ & $1.6 \pm 0.7$ \\
Gestational age & $39.8 \pm 1.4$ & $40.2 \pm 1.1$ \\
Delivery (vaginal/cesarean section) & $9 / 1$ & $9 / 1$ \\
\hline
\end{tabular}

* Mean \pm SD. 
Table 2. Nutrient intakes of breast-fed and formula-fed infants*

\begin{tabular}{lcc}
\hline & $\begin{array}{c}\text { Breast-fed } \\
(n=9)\end{array}$ & $\begin{array}{c}\text { Formula-fed } \\
(n=10)\end{array}$ \\
\hline $\begin{array}{l}\text { Energy } \\
\mathrm{kJ} / \mathrm{d}\end{array}$ & \\
$\mathrm{kJ} \cdot \mathrm{kg}^{-1} \cdot \mathrm{d}^{-1}$ & $2071 \pm 376$ & $2385 \pm 397$ \\
Protein & & $351 \pm 54$ \\
$\mathrm{~g} / \mathrm{d}$ & $6.7 \pm 1.6 \dagger$ & $9.6 \pm 3.3$ \\
$\mathrm{~g} \cdot \mathrm{kg}^{-1} \cdot \mathrm{d}^{-1}$ & $1.0 \pm 0.2 \dagger$ & $1.8 \pm 0.3$ \\
$\mathrm{Lactose}$ & & \\
$\mathrm{g} / \mathrm{d}$ & $51.4 \pm 10.0$ & $58.9 \pm 9.8$ \\
$\mathrm{~g} \cdot \mathrm{kg}^{-1} \cdot \mathrm{d}^{-1}$ & $7.4 \pm 1.2 \dagger$ & $8.7 \pm 1.3$ \\
$\mathrm{Fat}$ & & \\
$\mathrm{g} / \mathrm{d}$ & $23.8 \pm 6.3 \dagger$ & $29.5 \pm 4.9$ \\
$\mathrm{~g} \cdot \mathrm{kg}^{-1} \cdot \mathrm{d}^{-1}$ & $3.4 \pm 0.9 \dagger$ & $4.4 \pm 0.7$ \\
\hline
\end{tabular}

$*$ Values are mean $\pm \mathrm{SD}$.

$\dagger$ Significantly different from formula-fed group, $p<0.05$ ( $t$ test $)$. + Significantly different from formula-fed group, $p<0.001$ ( $t$ test).

Table 3. Nocturnal sleep characteristics of breast-fed and formula-fed infants*

\begin{tabular}{lcc}
\hline & $\begin{array}{c}\text { Breast-fed } \\
(n=10)\end{array}$ & $\begin{array}{c}\text { Formula-fed } \\
(n=10)\end{array}$ \\
\hline Total monitoring time (min) & $601 \pm 18 \dagger$ & $584 \pm 18$ \\
Total sleep time & $399 \pm 83$ & $464 \pm 73$ \\
$\quad$ min & $66.3 \pm 13.9 \dagger$ & $79.4 \pm 12.5$ \\
$\quad$ monitoring time & $2.9 \pm 1.8$ & $2.7 \pm 2.0$ \\
Awakenings (number) & $2.1 \pm 0.4$ & $2.2 \pm 0.5$ \\
Sleep transitions (number/h) & $7.4 \pm 2.1$ & $8.8 \pm 2.4$ \\
Sleep cycles (number) & $56.5 \pm 12.9$ & $54.7 \pm 9.6$ \\
Sleep cycle duration (min) & $34.3 \pm 41.6 \dagger$ & $4.0 \pm 12.6$ \\
Sleep latency (min) & $69.5 \pm 52.9$ & $99.0 \pm 85.4$ \\
REM latency (min) & & \\
Total time in NREM & $261 \pm 41$ & $266 \pm 30$ \\
$\quad$ min & $66.1 \pm 4.8 \ddagger$ & $57.9 \pm 5.6$ \\
$\quad \%$ sleep time & $138 \pm 45 \ddagger$ & $198 \pm 54$ \\
Total time in REM & $33.9 \pm 4.8 \ddagger$ & $42.1 \pm 5.6$ \\
$\quad$ min & $8.7 \pm 1.8$ & $10.2 \pm 2.0$ \\
$\quad \%$ sleep time & $7.6 \pm 2.4$ & $9.2 \pm 2.3$ \\
NREM epochs (number) & $29.1 \pm 4.9$ & $26.8 \pm 4.3$ \\
REM epochs (number) & $18.6 \pm 3.2 \ddagger$ & $22.5 \pm 2.8$ \\
Duration NREM epochs (min) & & \\
Duration REM epochs (min) & $114 \pm 9 \ddagger$ & $126 \pm 6$ \\
Heart rate & $112 \pm 10 \ddagger$ & $124 \pm 7$ \\
$\quad$ Total sleep (bpm) & $118 \pm 8 \ddagger$ & $129 \pm 6$ \\
NREM (bpm) & $123 \pm 13 \ddagger$ & $137 \pm 5$ \\
REM (bpm) & & \\
Awake (bpm) & & \\
\hline
\end{tabular}

$*$ Values are mean $\pm \mathrm{SD}$.

$\uparrow$ Significantly different from formula-fed group, $p<0.05$ ( $t$ test).

$\ddagger$ Significantly different from formula-fed group, $p<0.01$ ( $t$ test).

$2.2 \pm 0.9$ times for $32 \pm 23$ min per feeding; formula-fed infants were fed $2.0 \pm 0.8$ times for $22 \pm 12$ min per feeding. EEG characteristics in all subjects were normal and showed appropriate developmental features during awake and sleep states. Oxygen saturation values remained above $90 \%$ except for a few transient, self-corrected drops.

The total number and duration of sleep cycles, number of sleep transitions, REM latency, number of NREM and REM epochs, and duration of NREM epochs did not differ between feeding groups. Sleep transitions lasting less than 2 min occurred in only three of the breast-fed infants (an average of $1.7 \pm 0.6$ times) and in five of the formula-fed infants (an average of 1.4 \pm 0.9 times). Sleep latency was significantly shorter in the formula-fed group $(p<0.05)$. All infants entered sleep through NREM sleep. The mean duration of REM epochs was significantly longer among the formula-fed infants $(p<0.01)$. The formula-fed infants spent a higher percentage of sleep time in REM sleep compared with the breast-fed infants $(p<0.003)$. In separate analyses in which the number of awakenings, total sleep time, and sleep time as a percentage of monitoring time were treated as covariates, the differences in sleep stage distribution remained statistically significant between feeding groups $(p<$ 0.03 ). Heart rates were lower among the breast-fed than the formula-fed infants while asleep and awake $(p<0.01)$. Heart rates were significantly lower during NREM than REM sleep for both groups $(p<0.001)$.

Sleep characteristics of the breast-fed and formula-fed infants were not significantly correlated with energy, lactose, or fat intakes. Protein intake $\left(\mathrm{g} / \mathrm{d}\right.$ or $\left.\mathrm{g} \cdot \mathrm{kg}^{-1} \cdot \mathrm{d}^{-1}\right)$ was positively correlated $(p<0.05)$ with total REM (min), REM (\% sleep time), heart rate, and duration of REM epoch and negatively correlated with NREM latency and NREM sleep (\% sleep time). The relationships between protein intake and sleep parameters were confounded by feeding mode. For instance, formula-fed infants had a higher mean protein intake $(p<0.001)$ and a higher percentage of sleep time in REM. Within feeding groups, there were no significant correlations between protein intake and any of the sleep parameters.

Calorimetric data were collected for $392 \pm 83 \mathrm{~min}$ for the breast-fed and $436 \pm 90 \mathrm{~min}$ for the formula-fed infants. Mean temperature within the calorimeter was $25.0 \pm 0.8^{\circ} \mathrm{C}$. Representative tracings of energy expenditure and sleep stage versus time are displayed in Figures 1 and 2. Energy expenditure increased markedly with the onset of REM sleep and then gradually declined through the REM epoch. Energy expenditure began to rise preceding the transition into REM in most instances. Energy expenditure, expressed as $\mathrm{kJ} / \mathrm{min}$ and $\mathrm{kJ} \cdot \mathrm{kg}^{-1}$. $\mathrm{min}^{-1}$, differed significantly by sleep stage $(p<0.001)$ (Table 4$)$. Energy expenditure during REM sleep was $13.0 \pm 4.4 \%$ higher than during NREM sleep $(p<0.001)$. As shown in Table 4 , rates of energy expenditure $\left(\mathrm{kJ} / \mathrm{min}\right.$ or $\left.\mathrm{kJ} \cdot \mathrm{kg}^{-1} \cdot \mathrm{min}^{-1}\right)$ during NREM, REM, and awake stages did not differ statistically by feeding group. Rates of energy expenditure during total sleep and NREM sleep were $0.161 \pm 0.017$ and $0.152 \pm 0.010 \mathrm{~kJ}$. $\mathrm{kg}^{-1} \cdot \mathrm{min}^{-1}$ for the formula-fed infants and $0.150 \pm 0.017$ and $0.142 \pm 0.017 \mathrm{~kJ} \cdot \mathrm{kg}^{-1} \cdot \mathrm{min}^{-1}$ for the breast-fed infants $(p<$ 0.10 ). RQ did not differ between sleep stages or feeding groups.

In a multiple regression model, the percentage of time in NREM (or REM) and heart rate accounted for $54 \%$ of the variability in sleeping energy expenditure $\left(\mathrm{kJ} \cdot \mathrm{kg}^{-1} \cdot \mathrm{min}^{-1}\right)$. The partial coefficients for the percentage of time in NREM $(-0.09$ $\mathrm{kJ} \cdot \mathrm{kg}^{-1} \cdot \mathrm{min}^{-1}$ per $1 \%$ change; $\left.p<0.04\right)$ and heart rate $(0.004$ bpm per $1 \%$ change; $p<0.02$ ) contributed independently and significantly to sleeping energy expenditure.

\section{DISCUSSION}

Nocturnal sleep organization of the infants in our study was affected differently by breast-feeding or formula feeding. Although the sleep stage distributions were considered normal for infants 4 mo of age, the differences in the partitioning of sleep into REM and NREM between breast-fed and formula-fed infants raised intriguing questions about possible causes and physiologic implications. Identification of the causal agent is not feasible in this observational study. Differences in the intake of macronutrients, minerals, vitamins, and other bioactive constituents and in behavioral entrainment are among the numerous possible explanations.

NREM sleep time, as a percentage of total sleep time, was greater for infants fed human milk than for infants fed a caseinpredominant formula; conversely, REM sleep time (absolute amount and as a percentage of total sleep time) was greater for formula-fed infants. The REM epochs of the formula-fed infants were also longer than those of infants fed human milk. In the laboratory, the total sleep time of breast-fed infants, in absolute terms and as a percentage of monitoring time, was less than that 


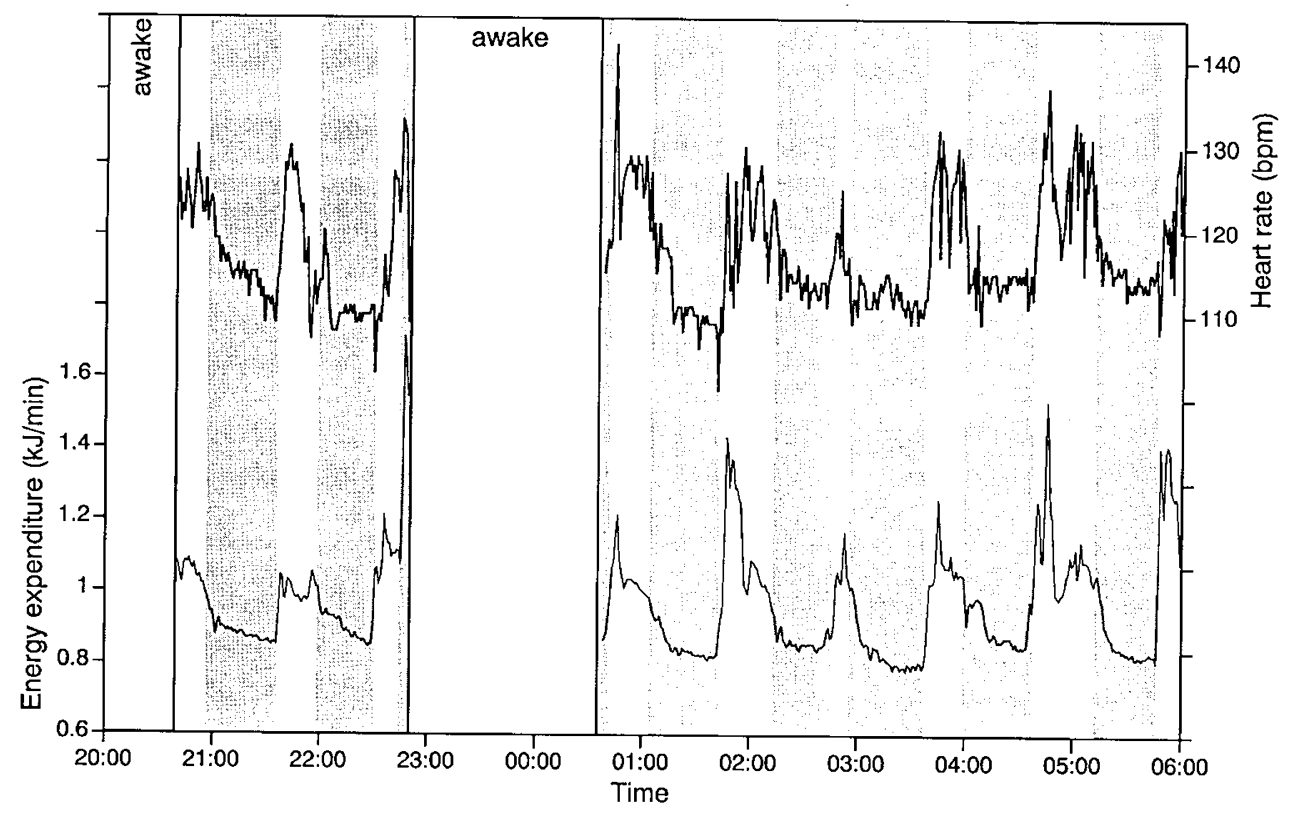

Fig. 1. Tracing of the energy expenditure (bottom) and heart rate (top) of a breast-fed infant during REM ( $\square$ ) and NREM ( ) sleep.

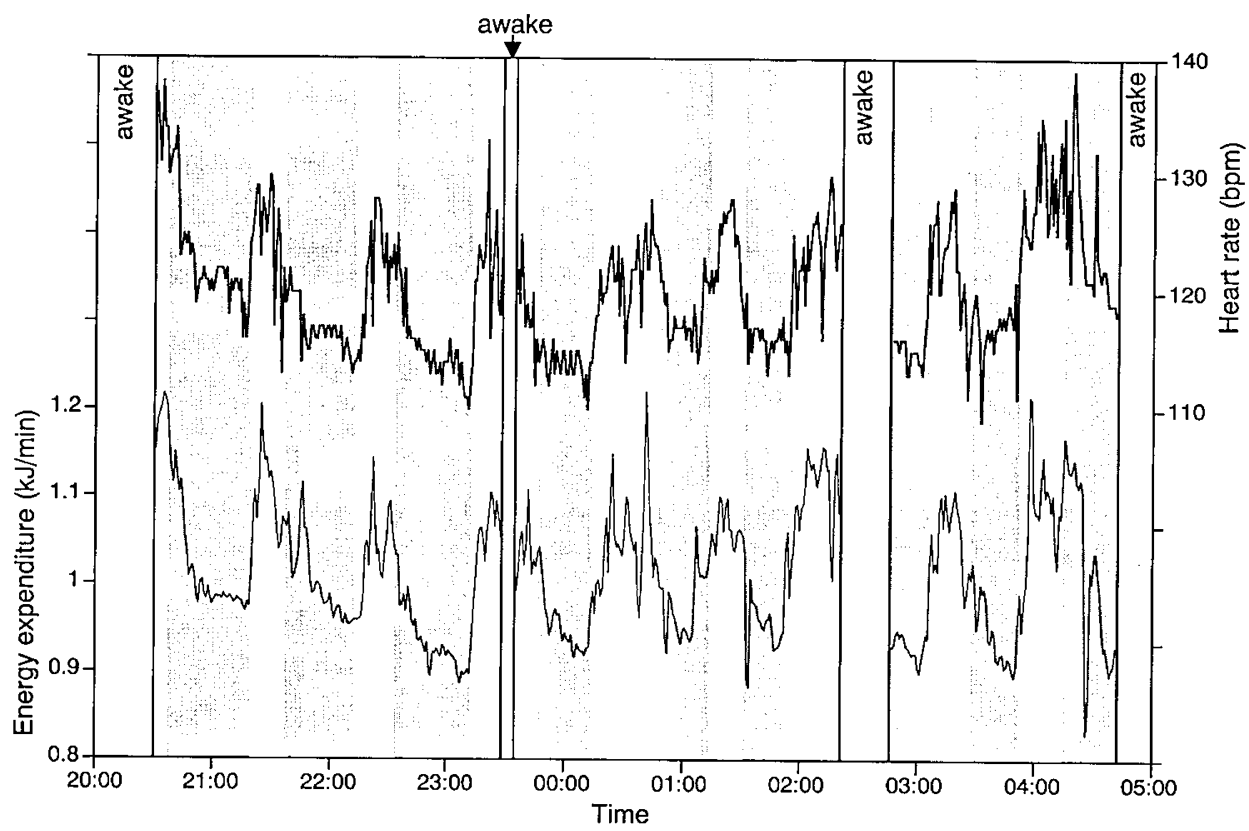

Fig. 2. Tracing of the energy expenditure (bottom) and heart rate (top) of a formula-fed infant during REM ( $\square$ ) and NREM ( ) sleep.

of the formula-fed infants, but the sleep latency was longer, even though the infants were subjected to the same procedures. With an adjustment for these variables, however, the proportions of REM and NREM sleep were still significantly different between feeding groups. Some disruption was seen in usual nocturnal sleep time in both feeding groups. Although total nocturnal sleep time was longer at home, relative differences in sleep partitioning between feeding groups would be expected. The other sleep characteristics that were measured did not differ between feeding groups and were considered normal for the age of the infants (17). There was no evidence that the periodicity or continuity of sleep states differed between feeding groups; the values were in agreement with previous reports (5).

The circadian sleep patterns of the infants recorded in the home diaries were well developed, although the breast-fed infants had less uninterrupted nocturnal sleep time than the formulafed infants. Usual nocturnal bedtime did not differ between feeding groups. Records of milk intake at home indicated that the breast-fed infants had more nocturnal (0000 and $0600 \mathrm{~h}$ ) feedings than the formula-fed infants. Although statistically insignificant, the breast-fed infants tended to feed more frequently and longer than the formula-fed infants during the sleep study. Behavioral entrainment may differ between feeding groups.

Our findings do not agree with a comparative study on sleep behavior of breast-fed and formula-fed infants (18), in which breast-fed infants had shorter latencies to REM sleep and longer sleep times than formula-fed infants. Differences in the ages of the infants, monitoring times, and sleep-staging methodologies between the studies may account for the discrepancies.

We did not detect significant associations between sleep characteristics and intakes of energy, fat, or lactose. Protein intake was correlated positively with REM sleep and negatively with NREM sleep. Because of the high correlation between protein intake and feeding mode, however, their effects on sleep behavior could not be separated in the present design. Other quantitative or qualitative differences in the composition of, or intake from, 
Table 4. Energy expenditure (EE) of breast-fed and formula-fed infants*

\begin{tabular}{|c|c|c|}
\hline & $\begin{array}{c}\text { Breast-fed } \\
(n=10)\end{array}$ & $\begin{array}{c}\text { Formula-fed } \\
(n=10)\end{array}$ \\
\hline$\dot{\mathrm{V}}_{2}(\mathrm{~L} / \mathrm{min})$ & $0.049 \pm 0.007$ & $0.051 \pm 0.006$ \\
\hline$\dot{\mathrm{V}}_{\mathrm{CO}_{2}}(\mathrm{~L} / \mathrm{min})$ & $0.044 \pm 0.006$ & $0.047 \pm 0.005$ \\
\hline \multicolumn{3}{|l|}{$\mathrm{EE}$} \\
\hline \multicolumn{3}{|l|}{ Total sleep } \\
\hline $\mathrm{kJ} / \mathrm{min}$ & $1.015 \pm 0.141$ & $1.060 \pm 0.122$ \\
\hline $\mathrm{kJ} \cdot \mathrm{kg}^{-1} \cdot \mathrm{min}^{-1}$ & $0.150 \pm 0.017$ & $0.161 \pm 0.011$ \\
\hline \multicolumn{3}{|l|}{ NREM } \\
\hline $\mathrm{kJ} / \mathrm{min}$ & $0.951 \pm 0.128$ & $1.000 \pm 0.114$ \\
\hline $\mathrm{kJ} \cdot \mathrm{kg}^{-1} \cdot \min ^{-1}$ & $0.142 \pm 0.017$ & $0.152 \pm 0.010$ \\
\hline \multicolumn{3}{|l|}{ REM } \\
\hline $\mathrm{kJ} / \mathrm{min}$ & $1.088 \pm 0.151$ & $1.114 \pm 0.117$ \\
\hline $\mathrm{kJ} \cdot \mathrm{kg}^{-1} \cdot \min ^{-1}$ & $0.162 \pm 0.019$ & $0.170 \pm 0.011$ \\
\hline \multicolumn{3}{|l|}{ Awake } \\
\hline $\mathrm{kJ} / \mathrm{min}$ & $1.226 \pm 0.297$ & $1.334 \pm 0.288$ \\
\hline $\mathrm{kJ} \cdot \mathrm{kg}^{-1} \cdot \mathrm{min}^{-1}$ & $0.182 \pm 0.040$ & $0.197 \pm 0.030$ \\
\hline \multicolumn{3}{|l|}{$\mathrm{RQ}$} \\
\hline Total sleep & $0.896 \pm 0.025$ & $0.910 \pm 0.025$ \\
\hline NREM & $0.892 \pm 0.025$ & $0.906 \pm 0.028$ \\
\hline REM & $0.904 \pm 0.024$ & $0.917 \pm 0.021$ \\
\hline Awake & $0.867 \pm 0.038$ & $0.853 \pm 0.039$ \\
\hline
\end{tabular}

* Values are mean $\pm \mathrm{SD}$.

human milk and formula may affect sleep. Specific biologically active proteins exist in human milk, such as prolactin, growth hormone releasing factor, vasoactive intestinal peptide, deltasleep-inducing peptide, nerve growth factor, and casomorphins, which may influence sleep behavior (19). Differences in the content of long-chain polyunsaturated fatty acids may be manifested in altered brain phospholipids which may affect neural function (20).

The lower heart rates of the breast-fed infants across all sleep stages corroborated our earlier findings of lower mean 18 -h heart rates in breast-fed than in formula-fed infants (21). DiPietro et al. (22) reported lower heart rates, greater heart rate variability, and higher vagal tone in breast-fed than in formula-fed infants studied 17 to $56 \mathrm{~d}$ postpartum. Their findings suggest an acute rather than a chronic effect of feeding mode. Higher vagal tone and slower heart rate are indicative of higher parasympathetic inhibitory output. The fall in heart rate during the shift from wakefulness to NREM sleep is caused by an increase in vagal tone (23). An accelerated heart rate associated with bursts of REM results when vagal activity is inhibited, whereas the bradycardia that follows results when sympathetic output is inhibited and vagal discharge is increased. In accord with these physiologic changes, the mean heart rates of our infants differed significantly with infant state.

The energy expenditure of infants generally has been shown to be higher during REM than during NREM sleep. In 30 fullterm newborn infants, $\dot{\mathrm{V}}_{2}$ increased $6.6 \%$ in the transition from NREM to REM (7). In another series of seven neonates, a $9.4 \%$ increase in $\mathrm{V}_{2}$ was shown in the transition from NREM to REM (9). Equivocal results have been reported for preterm infants: Scopes and Ahmed (8) detected a $16 \%$ increase in $\dot{\mathrm{V}}_{2}$, and Darnall and Ariagno (24) showed no difference in $\dot{\mathrm{V}}_{2}$ between REM and NREM. Conflicting results have been reported on adults; some investigators have detected significant increases in energy expenditure during REM sleep $(25,26)$, whereas others have not $(27,28)$. In our study, energy expenditure was clearly shown to be higher during REM sleep, and a distinct pattern of energy expenditure was also evident during the REM epoch.

The increase in energy expenditure during REM sleep is consistent with the physiologic and biochemical changes that occur in the transition from NREM to REM (29); heart rate and respiration rates are more variable, blood pressure increases, and regional blood flow to the thalamus, hypothalamus, and brainstem are higher during REM than NREM sleep (30). CNS $\dot{\mathrm{VO}}_{2}$ and glucose use increase diffusely during REM sleep and result in increased brain temperature. During REM sleep, there is considerable physical activity which consists of facial, limb, and whole body movements (31).

The pattern of neuronal activation before and throughout an REM episode is consistent with the marked increase in energy expenditure before and during REM. Hobson et al. (32) proposed an REM-sleep oscillator system dependent on excitatory cholinergic neurons, which became activated before and during REM sleep and reciprocally interacted with inhibitory aminergic neurons whose discharge activity diminished before and ceased during REM. Before REM onset, and during the REM episode, there is a membrane potential depolarization of the pontine reticular formation neurons. McCarley and Massaquoi (33) have suggested that the reticular neuron membrane depolarization activates neurons within the pontine reticular formation and causes the REM, muscle twitches, and muscular atonia seen in REM sleep.

We can only speculate on the physiologic significance of the differences in sleep stage distribution between feeding groups. It may be argued that maturation of the CNS is accelerated in breast-fed infants. The high proportion of REM sleep in early infancy may stimulate CNS activity and thereby facilitate the growth and maturation of the CNS; the diminution of REM sleep as the infant develops reflects the maturation of the CNS (34). NREM, a highly controlled state dependent on higher cerebral centers, seems to require complex feedback mechanisms to maintain regular respiration and heart rate and to inhibit body movement (35). Alternatively, it may be argued that these observations reflect an acute feeding effect of nutrients or other biologically active substances on sleep organization. The factor(s) accountable for the differences in sleep organization between breast-fed and formula-fed infants has yet to be identified.

Acknowledgments. The authors thank B. Harlan, S. Parker, J. C. Young, D. Wolf, N. Mehta, J. Davis-Street, and A. Adolph for their technical assistance; A. Cavese and C. Fedrick for manuscript preparation; J. D. Eastman and E. R. Klein for editorial review; and the parents who permitted their infants to participate in this study. We also thank Ross Laboratories for their formula donations.

\section{REFERENCES}

1. Yogman MW, Zeisel SH 1985 Nutrients, neurotransmitters and infant behavior. Am J Clin Nutr 42:352-360

2. Janas LM, Picciano MF, Hatch TF 1987 Indices of protein metabolism in term infants fed either human milk or formulas with reduced protein concentration and various whey/casein ratios. J Pediatr 110 : 838-848

3. Yogman MW, Zeisel SH 1983 Diet and sleep patterns in newborn infants. N Engl J Med 309:1 147-1149

4. Roffwarg HP, Muzio JN, Dement WC 1966 Ontogenetic development of the human sleep-dream cycle. Science 152:604-619

5. Harper RM, Leake B, Miyahara L, Mason J, Hoppenbrouwers T, Sterman MB, Hodgman J 1981 Temporal sequencing in sleep and waking states during the first 6 months of life. Exp Neurol 72:294-307

6. Butte N, Wong WW, Ferlic L, Smith EO, Klein PD, Garza C 1990 Energy expenditure and deposition of breast-fed and formula-fed infants during early infancy. Pediatr Res 28:631-640

7. Stothers JK, Warner RM 1978 Oxygen consumption and neonatal sleep states. f Physiol 278:435-440

8. Scopes JW, Ahmed I 1966 Minimal rates of oxygen consumption in sick and premature newborn infants. Arch Dis Child 41:407-416

9. Kairam R, Schulze K, Koenigsberger M, James LS 1979 The effects of changing sleep states on autonomic functions in the newborn. Pediatr Res 13: 498 (abstr)

10. Kellaway P, Frost Jr JD 1985 Monitoring at the Baylor College of Medicine, Houston. Long-term Monitoring in Epilepsy (EEG Suppl. No. 37). Gotman J, Ives JR, Gloor P (eds) Elsevier Science Publishers B.V., New York

11. Hrachovy RA, Frost JD, Kellaway P 1981 Sleep characteristics in infantile spasms. Neurology 31:688-694

12. Frost Jr JD, Hrachovy RA, Kellaway P, Zion $\Upsilon 1978$ Quantitative analysis and characterization of infantile spasms. Epilepsia 19:273-282 
13. de V Weir JB 1949 New methods for calculating metabolic rate with special reference to protein metabolism. J Physiol 109:1-9

14. Jeejeebhoy KN, Ahmad S, Kozak G 1970 Determination of fecal fats containing both MCT, LCT, and fatty acids. Clin Biochem 3:157-163

15. Minitab version 6.1 1988 Minitab, Inc., State College, PA

16. Dixon WJ (ed) 1983 BMDP, Biomedical Computer Programs. University of California Press, Berkeley, CA.

17. Parmelee Jr AH, Wenner WH, Schulz HR 1964 Infant sleep patterns: from birth to 16 weeks of age. J Pediatr 65:576-582

18. Steinberg L, Birch LL, Picciano MF, Goff N 1989 Infant nutrition and behavior: neonatal behavioral assessment scale (NBAS) differences among infants fed formula varying in tryptophan. FASEB J 3:A765(abstr)

19. Britton JR, Kastin AJ 1991 Biologically active polypeptides in milk. Am J Med Sci 301:124-132

20. Koletzko B, Bremer HJ 1989 Fat content and fatty acid composition of infant formulas. Acta Paediatr Scand 78:513-521

21. Butte NF, Smith EO, Garza C 1991 Heart rates of breast-fed and formula-fed infants. J Pediatr Gastroenterol Nutr 13:391-396

22. DiPietro JA, Larson SK, Porges SW 1987 Behavioral and heart rate pattern differences between breast-fed and bottle-fed neonates. Dev Psychol 33: $467-474$

23. Baust W, Bohnert B 1969 The regulation of heart rate during sleep. Exp Brain Res 7:169-180

24. Darnall Jr RA, Ariagno RL 1982 The effect of sleep state on active thermoregulation in the premature infant. Pediatr Res 16:512-514

25. Brebbia R, Altshuler KZ 1965 Oxygen consumption rate and electroencephalographic stage of sleep. Science 150:1621-1623
26. Haskell EH, Palca JW, Walker JM, Berger RJ, Heller HC 1981 Metabolism and thermoregulation during stages of sleep in humans exposed to heat and cold. J Appl Physiol 51:948-954

27. Ryan T, Mlynczak S, Erickson T, Man SFP, Man GCW 1989 Oxygen consumption during sleep: influence of sleep stage and time of night. Sleep 12: 201-210

28. Webb P, Hiestand M 1975 Sleep metabolism and age. J Appl Physiol 38: 257-262

29. Montplaisir J, Godbout R (eds) 1990 Sleep and Biological Rhythms: Basic Mechanisms and Applications to Psychiatry. Oxford University Press, New York

30. Cote A, Haddad GG 1990 Effect of sleep on regional blood flow distribution in piglets. Pediatr Res 28:218-222

31. Anders T, Emde R, Parmelee A (eds) 1971 A Manual of Standardized Terminology, Techniques and Criteria for Scoring of States of Sleep and Wakefulness in Newborn Infants. NINDS Neurological Information Network, UCLA Brain Information Service/BRI Publications Office, Los Angeles, CA, pp 111

32. Hobson JA, McCarley RW, McKenna TM 1976 Cellular evidence bearing on the pontine brain-stem hypothesis of desynchronized sleep control. Prog Neurobiol 6:279-359

33. McCarley RW, Massaquoi SG 1981 A limit cycle mathematical model of the REM sleep oscillatory system. Am J Physiol 251:R1011-R1029

34. Denenberg VH, Thoman EB 1981 Evidence for a functional role for active (REM) sleep in infancy. Sleep 4:185-191

35. Stern E, Parmelee AH, Akiyama Y, Schultz MA, Wenner WH 1969 Sleep cycle characteristics in infants. Pediatrics 43:65-70 